\section{RMD Open}

Rheumatic \&

Musculoskeletal Diseases

To cite: Gossec L, Dougados M, Dixon W. Patient-reported outcomes as end points in clinical trials in rheumatoid arthritis. RMD Open 2015;1:e000019. doi:10.1136/rmdopen-2014000019

- Prepublication history for this paper is available online. To view these files please visit the journal online (http://dx.doi.org/10.1136/ rmdopen-2014-000019).

Received 16 February 2015 Revised 10 March 2015 Accepted 11 March 2015
CrossMark

For numbered affiliations see end of article.

Correspondence to Professor Laure Gossec; laure.gossec@psl.aphp.fr

\title{
Patient-reported outcomes as end points in clinical trials in rheumatoid arthritis
}

\author{
Laure Gossec,, ${ }^{1,2}$ Maxime Dougados, ${ }^{3,4}$ William Dixon ${ }^{5}$
}

\section{ABSTRACT}

There is a growing interest in patient-reported outcomes (PROs) in rheumatology, which goes with a global trend for more 'patient-centred care'. This review considers the use of PROs in trials, including their strengths and limitations. In rheumatoid arthritis (RA) trials, the most frequently used PROs to assess treatments include pain, patient global assessment, assessment of functional status, but also health-related quality of life and less commonly fatigue. Other aspects of importance for patients, such as sleep, psychological well-being or ability to cope, are rarely assessed. PROs as outcome measures in RA trials have strengths as well as limitations. PROs have face validity, they are reproducible and sensitive to change and they bring additional information beyond joint counts or acute phase reactants. However, their predictive validity for later outcomes has been little explored, some PROs show redundancy (they bring similar information) and, due to the apparently moderate link between some PROs such as fatigue and the disease process, the use of some PROs to inform treatment choices has been questioned. We suggest the choice of PROs for trials depends on the study objective and on the viewpoint of the stakeholder. There needs to be agreed prioritisation across all stakeholders about what is most important to collect in a trial, which is why a prioritisation and selection process is necessary. Trials in RA will continue to include PROs and their interpretation will become easier as our knowledge progresses.

\section{INTRODUCTION-THE PLACE OF PATIENT REPORTED OUTCOMES AMONG OUTCOME MEASURES}

Rheumatoid arthritis (RA) is a systemic, inflammatory condition with short-term and with long-term consequences for patients. ${ }^{1}$ The inflammatory process leads to symptoms either directly (such as pain) or more indirectly (such as fatigue, emotional and social consequences), and also leads to long-term joint damage, which itself leads to symptoms such as pain and disability (figure 1). Trials study how drugs affect the process of RA and, importantly, its consequences, which

\section{Key messages}

What is already known on this subject?

Patient reported outcomes (PROs) in rheumatoid arthritis (RA) trials reflect the patient's perspective; they have good psychometric properties, and they bring additional information beyond joint counts or acute phase reactants.

What might this study add?

PROs have some limitations that include lack of data on their predictive validity for later outcomes, inter-PRO redundancy (they bring similar information) and a moderate link between some PROs such as fatigue and the disease process.

How might this impact on clinical practice?

- This review suggests PROs should be assessed in clinical trials though treatment choices should not be based solely on PRO results.

requires measurement of these various aspects of RA: inflammation, symptoms and joint damage. For some of these domains, it is impossible for the clinician to provide a formal objective assessment through either examination or investigations.

Patient reported outcomes (PROs) are reports coming directly from patients about how they feel or function in relation to a health condition and its therapy without interpretation by healthcare professionals or anyone else. PROs can relate to symptoms, signs, functional status, perceptions or other aspects such as convenience and tolerability. ${ }^{2}$ To understand how patients are doing, and how arthritis is affecting pain or mobility, it is logical to ask the patient directly, using PROs. ${ }^{3-5}$ Indeed, there is a growing interest in PROs in rheumatology, in trials, observational studies and routine clinical practice, which goes with a global trend for more 'patient-centred care' and for better shared decision-making. ${ }^{5-9}$

An outcome measure should reflect what we want to achieve ( $\mathrm{eg}$, in headache, resolution of pain as soon as possible). It is complex in RA, since we have two objectives: the first is symptom resolution, that is, to 
Figure 1 The pathway in rheumatoid arthritis and examples of some frequent outcome measures.

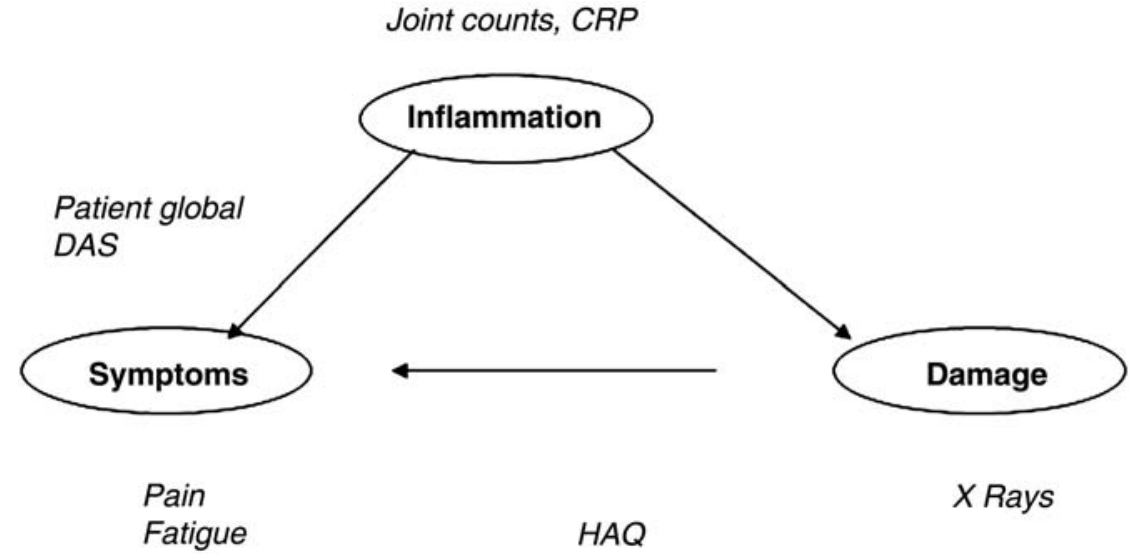

improve the current symptomatic condition as soon as possible; the second objective ("the preventative approach') aims to prevent subsequent structural deterioration. PROs are clearly valuable in assessing symptoms, but their role in assessing inflammation and/or damage is less clear.

In this article, we will review which PROs are used and how PROs are chosen for trials, then discuss the strengths and limitations of PROs.

\section{WHICH PROS IN RA TRIALS?}

There are many PROs available for RA trials: some are generic and others have been developed specifically for RA. ${ }^{10-12}$ Collectively, they provide a wide spectrum of PROs that covers many of the possible outcomes in a trial, including direct (eg, pain) and indirect (eg, sleep disturbance) outcomes. However, a balance must be reached in trials to take into account, on the one hand, what should ideally be collected and, on the other hand, what is feasible to collect in terms of patient burden. Clinical trialists make different decisions about which PROs to include in their studies. To illustrate, a review of 109 articles published on RA in 2008 included 50 randomised controlled trials; ${ }^{13}$ of these trials, $90 \%$ reported functional disability, $74 \%$ patient global assessment and $70 \%$ pain; other domains of health were less frequently reported: generic quality of life in $22 \%$, coping in $10 \%$, fatigue in $4 \%$ and sleep disturbance in $2 \%$ (table 1$){ }^{13}$

\section{HOW ARE PROS CHOSEN? DIFFERENT VIEWPOINTS MAY MODIFY THE CHOICE}

Trials need to meet the needs of a range of stakeholders. For each stakeholder, the interest may be in a different part, or parts, of the pathway of RA (ie, inflammation, symptoms or damage, figure 1). The balance in the use of PROs is thus dependent on what one is studying.

\section{Choosing PROs based on physician consensus}

Twenty years ago, experts from the American College of Rheumatology (ACR), the European League Against Rheumatism (EULAR) and Outcome Measures in Rheumatology (OMERACT) decided, through consensus, on a Core Set of variables to be collected in clinical trials of RA. ${ }^{14-16}$ On top of joint counts and acute phase reactants, the Core Set initially comprised three PROs: pain, patient global assessment and functional capacity (table 1). More recently, and based in particular on

Table 1 Frequently reported PROs in RA versus PROs proposed by different viewpoints

\begin{tabular}{llll}
\hline $\begin{array}{l}\text { Domains of health } \\
\text { assessed by PROs }\end{array}$ & $\begin{array}{l}\text { Frequency of reporting in } \mathbf{5 0} \\
\text { trials according to a systematic } \\
\text { literature review } \mathbf{( \% )} \mathbf{~}^{\mathbf{1 3}}\end{array}$ & $\begin{array}{l}\text { PROs in the enlarged Core } \\
\text { Set of variables to report in } \\
\text { RA trials } \mathbf{1 4}^{\mathbf{1 7}}\end{array}$ & $\begin{array}{l}\text { Domains of health most } \\
\text { important for patients } \\
\text { with RA }^{\mathbf{2 0}-23}\end{array}$ \\
\hline Pain & 70 & Yes & Yes \\
Patient global assessment & 74 & Yes & Yes \\
Functional capacity & 90 & Yes & Yes \\
Fatigue & 4 & Yes & Yes \\
Health-related quality of life & 22 & & Yes \\
Psychological distress & 4 & & Yes \\
Ability to cope & 10 & & Yes \\
Well-being & 0 & & Yes \\
Sleep & 2 & & \\
Work and social life & Productivity loss 2 & & \\
\hline
\end{tabular}

*Patient global assessment is not identified as a concept that is important for patients with RA, in qualitative studies. PROs, patient-reported outcomes; RA, rheumatoid arthritis. 
input from patient research partners, fatigue was added by OMERACT consensus to the Core Set. ${ }^{17}$ The same domains have been confirmed as important to report by an ACR/EULAR consensus. ${ }^{18}$ The Core Set consensus on the domains to report in RA, has been well implemented. ${ }^{13} 19$

\section{Choosing PROs based on their importance for patients with RA}

In RA, there is now a wealth of qualitative studies allowing us to better understand the impact of the disease on patients' lives. Several publications issued from patient group discussions or patient focus groups indicate that some domains or areas of health that are important for patients are little recognised in RA, both in trials and in clinical practice. ${ }^{20-22}$ These domains include, on top of pain and function: fatigue, well-being, sleep, psychological distress, ability to cope and the final consequences of the disease impact, including ability to work and to have a family and social life (table 1) ${ }^{20-23}$ Note that these are weighted towards short-term symptoms. When they are longer term outcomes, the outcome measures are the consequences of damage rather than radiographic changes.

When choosing PROs to assess in trials, patients with RA may want more domains than just those of the Core Set, because they would want to assess the efficacy of the drug on all the domains they are considering important for them, such as fatigue or sleep disturbances (table 1). ${ }^{20-23}$ One solution would be to include further PROs, but this adds further burden to the participants and risks loss to follow-up. Thus we have a situation of balance: ideal domains for clinicians versus ideal domains for patients versus feasibility.

\section{Choosing PROs for trials: the pharmaceutical industry's perspective}

For pharmaceutical industry-funded trials, the outcome measures are quite logically based first on a regulatory perspective, that is, on the need to obtain an authorisation and labelling claims. In RA, for disease modifying drugs and in particular for biologics, authorisations include demonstration of symptomatic effects (measured by PROs) as well as demonstration of a "preventative approach'. ${ }^{9}$ For this preventative approach, the main outcome is the short-term (eg, 6 months to 1 year) change in the scoring of structural damage on X-rays; for this objective, PROs are not usually used.

To obtain reimbursement, a new drug need to demonstrate cost-efficacy, for example, through Health Technology assessments (for the UK). ${ }^{24} 25$ Then the drug needs to be marketed to the populations that will prescribe or take the drug. The pharmaceutical industry may thus sometimes add PROs not critical for licensing in their trials if they add benefit for later marketing and communication, in particular towards patients. ${ }^{25}$

Licensing requires regulators to approve a benefits/ harm balance, but the benefit metric is often unclear. Recently, to advance the field of PROs for trials in particular in RA, a PRO Consortium has been set up. This 'Critical-Path' or C-Path Consortium consists of representatives from pharmaceutical, biotechnology, device and diagnostic companies, as well as Food and Drug Administration and National Institutes of Health (NIH). The announced objectives are to facilitate the identification, prioritisation and development (if needed) of potential PRO instruments. The next years will allow us to assess potential progress made.

\section{Choosing PROs: the society/payors' perspective}

The objective from society's viewpoint is to evaluate the cost incurred/saved by a treatment and, usually, payors want to be in a position to evaluate cost-effectiveness using generic tools evaluating quality of life, such as EuroQoL-five dimensions questionnaire, EQ-5D or the Short-form Health Survey, SF-36. Though these are valid questionnaires, patients feel this is not measuring what they want to report about their RA. However, these are accepted cost utility measures, hence there is some tension between what needs to be measured versus what patients want to report.

In summary, PROs can be used to measure a range of different outcomes in clinical trials. These should be viewed as an additional method of collecting information, rather than in competition with physician-derived measures such as joint counts. Clinicians sometimes argue that PROs are useless, subjective and/or lack validity. However, PROs are the only way to assess some of the aspects related to RA, for example, symptoms. Clinician-reported and PROs should be seen as complementary. In selecting outcomes for trials, there needs to be a balance between what to collect, from whom, and the burden of entry. This therefore requires an understanding of the properties of PROs, which will be discussed in the next section.

\section{The strong points of PROs}

PROs, like other outcome measures, need to be valid that is, need to have good psychometric properties. ${ }^{26}$ This is largely the case as we will see (table 2).

\section{PROs incorporate patient perspectives}

We have seen above that patients consider the measurement of subjective outcomes such as pain as important. It seems common sense, therefore, that such outcomes should be patient-reported, meeting the criteria of facevalidity (the extent to which a test is subjectively viewed as covering the concept it purports to measure). PROs bring unique information that cannot be collected from a physician and useful information, in particular, on symptoms.

\section{PROs have good psychometric properties}

PROs have face and construct validity, and are as reproducible as joint counts. ${ }^{12} 2627$ They may, however, pose problems of wording-which is not the case for objective, numerical measures, for example, $\mathrm{C}$ reactive protein 
Table 2 Some strengths and weaknesses of PROs

\begin{tabular}{lll}
\hline $\begin{array}{l}\text { The pathway } \\
\text { in RA }\end{array}$ & $\begin{array}{l}\text { The strong points of } \\
\text { PROs }\end{array}$ & $\begin{array}{l}\text { The weak points } \\
\text { of PROs }\end{array}$ \\
\hline Inflammation & & $\begin{array}{l}\text { PROs only } \\
\text { indirectly reflect } \\
\text { inflammation } \\
\text { Dymptoms } \\
\text { discordance } \\
\text { between the } \\
\text { physician and the } \\
\text { patient, in } \\
\text { treatment choices }\end{array}$ \\
& $\begin{array}{l}\text { PROs reflect the } \\
\text { patient's perspective } \\
\text { and symptoms }\end{array}$ & $\begin{array}{l}\text { Redundancy of } \\
\text { information }\end{array}$ \\
& $\begin{array}{l}\text { Information that is } \\
\text { distinct from } \\
\text { physician-derived } \\
\text { measures } \\
\text { Good psychometric } \\
\text { properties }\end{array}$ & $\begin{array}{l}\text { Development and } \\
\text { validation of } \\
\text { PROs not always } \\
\text { optimal }\end{array}$ \\
& & $\begin{array}{l}\text { Predictive validity } \\
\text { for structural } \\
\text { damage is limited } \\
\text { or unknown }\end{array}$ \\
\hline
\end{tabular}

PROs, patient-reported outcomes; RA, rheumatoid arthritis.

(CRP). When assessing single questions such as pain or patient global assessment, the wording of the questions is of great importance. In RA trials, heterogeneity is noted, ${ }^{13}$ in particular when assessing patient global assessment, which can be measured essentially using two different wordings: one related to general health visual analogue scale and the other to the patient's assessment of disease activity. ${ }^{28}{ }^{29}$ The results can differ, which is particularly important since patient global assessment is the only PRO included in the usual composite measures of disease activity such as the Disease Activity Score.

PROs have high feasibility: they are often at no cost (unless copyrighted), they are non-invasive and not painful, and do no require costly equipment. ${ }^{30}$ However, sometimes it may not be easy to have access to crossculturally validated questionnaires. This is why EULAR developed an Outcome Measures Library where validated translations are freely available. ${ }^{12} 31$

\section{PROs are sensitive to change}

In RA trials, PROs are as sensitive to change as objective measures of disease. In particular, pain and patient global assessment have been shown to be very sensitive to change. ${ }^{32}$

\section{Criterion validity: comparing the outcome to other outcomes known to be valid}

PROs bring information that is distinct from physicianderived measures. This can be shown by studies of discordance between the physician global assessment and the patient global assessment. In the largest study on discordance in patients with RA, 7028 patients with RA were assessed cross-sectionally. ${ }^{28}$ For $37 \%$ of them there was 'important' discordance (ie, a difference between the patient and physician global assessments of at least 2 points of 10). Thus even with the same question, we are getting different responses from the two groups (physicians and patients) in around one-third of patients with RA, indicating the two groups have a different understanding or perspective of the same question.

\section{Some limitations of PROs}

Here, we will discuss some aspects of PROs that we suggest are limitations (table 2). Some of the current limitations of PROs may be related to lack of data or lack of knowledge, and will warrant further research. Such limitations include the inefficiency of collecting overlapping PROs, challenges of validation and understanding the association with long-term outcomes.

\section{PROs and inflammation-do PROs help in the decision-making process?}

Although PROs bring, as we have seen, different and additional information, clinicians may feel that PROs are not the most useful data for the decision-making process and are superfluous. Treatment decisions for diseasemodifying drugs are mostly driven by inflammation, usually reflected by joint counts and/or CRP. What do PROs add to other knowledge?

In fact, when the patient's assessment and the physician's assessment are in agreement, either for low disease/remission or for high disease activity, treatment decisions based on the PROs would lead to the same decision as decisions derived from the physician assessment. However, discordance between the objective physician's assessment of RA and the patient's assessment of his/her status creates a tension of which measure should guide treatment decisions in clinical practice. In certain situations of discordance, such as high symptoms but absent inflammation, it could be argued that the type of discordance in fact guides treatment decisions. In this example, it might lead to no change of diseasemodifying drug treatments but changes in symptommodifying treatments and/or non-pharmacological measures.

In the context of trials, however, the situation is more complex. How should we assess the efficacy of a hypothetical drug that would effectively block the inflammatory pathways and negate visible inflammation without having any effects on the symptoms?

\section{PROs and symptoms}

\section{Potential inefficiency of collecting multiple PROs}

As we have seen, PROs are key to assessing symptoms. However, when assessing multiple PROs (eg, pain, fatigue and patient global assessment) there can be replication across different measurement instruments. Since, correlations between different PROs are around 
$0.6,{ }^{33}$ it may not be always necessary to assess all these PROs. Computer-assisted technology, such as is applied in the American PROMIS system, allows patients to assess several domains of health but through the completion of fewer questions. ${ }^{34}$ These types of personalised questionnaires may reduce the patient burden but will not solve the problem of redundant information from several PROs.

\section{How to deal with some symptoms, such as fatigue}

The case of fatigue in RA is of particular interest. Fatigue has been consistently shown to be important for patients with RA. ${ }^{20-23}$ Fatigue is described as intrusive and overwhelming in RA, and has consequences on all aspects of quality of life. ${ }^{35}$ Indeed, because of its importance for patients, fatigue data should be collected in trials (and probably in clinical practice too). ${ }^{17} 18$

However, questions arise when interpreting fatigue and in particular when making treatment decisions based on fatigue. Its link with disease activity is, at best, incomplete: the best models to explain fatigue in RA include disease activity (functional capacity and pain may explain $50 \%$ of fatigue), but also psychological distress (for around 30\%) as well as other factors, for example, poor sleep, beliefs, coping and behaviours. ${ }^{36}$ Thus, aspects of life probably unrelated to RA play a role in the genesis of fatigue in RA. Furthermore, the efficacy of usual treatments of RA, including biologics, on fatigue is only moderate. A meta-analysis indicated the effect size of biologics on RA fatigue was around 0.40 , which is a moderate effect size and would correspond to a decrease of $1.5-2$ points (on a $0-10$ scale) ${ }^{37}$ This raises questions regarding the interpretation of fatigue levels in trials. Clearly, further research is needed regarding fatigue.

\section{Are PROs rigorously developed and validated?}

PROs, like other outcomes measures, should be rigorously developed and validated. ${ }^{9}{ }^{38}$ However, many PROs published in rheumatology, have not been developed and/or validated according to these rules. ${ }^{12}$ In particular, although best practice principles for PRO development recognise the importance of involving patients as research partners when developing PROs, this is the case for very few of the RA PROs; some PROs with extensive patient involvement include the Bristol RA Fatigue Multi-Dimensional Questionnaire and Numerical Rating Scale (BRAF-MDQ BRAF-NRS), the RA Impact of Disease score or the RA Patient Priorities for Pharmacological Interventions outcome. ${ }^{92326333940}$

\section{PROs and damage-are PROs predictive of long-term outcomes?}

It is accepted that PROs are useful in measuring symptoms, but are they also useful in assessing long-term outcomes? Joint counts have been demonstrated to be predictive of long-term joint prognosis. As regards PROs, only the Health Assessment Questionnaire (HAQ) is known to be predictive of disability, mortality, health resource use and costs. ${ }^{30}$ However, the HAQ may not in fact bring additional predictive data, but rather redundant predictive data, compared to joint counts. It is noteworthy that when the ACR/EULAR) criteria to define remission in RA were developed, one PRO was included in the definition (patient global assessment); the other components being joints counts and acute phase reactants. ${ }^{41}$ As these criteria were developed based on predictive capacities for later joint destruction, it appears that patient global assessment may have an independent predictive capacity (on top of joint counts and acute phase reactants) to predict radiographic damage. $^{41}$

Overall, however, there is very limited knowledge of the predictive validity of other PROs. This needs to be further assessed.

\section{SUMIMARY}

The field of PROs in RA is of great interest, and is clearly relevant in these days of patient-centred care. In RA trials, PROs are important because they reflect the patient's perspective, and they bring additional and different information (given discordance of assessment between physicians and patients is around 30\%). Pain, function, patient global assessment and quality of life are the domains most frequently assessed in trials; however, they may not render a complete picture of the lives of patients with RA. Other aspects of importance for patients, such as sleep, psychological well-being or ability to cope, are rarely assessed. Using patient-reported composite scores such as the EULAR-developed RA Impact of Disease Score might be of use in RA trials. ${ }^{33}$

The information brought by PROs is relevant for patients, but also to healthcare providers and payers though sets of PROs to collect are different when based on these different viewpoints.

PROs have good psychometric properties and bring important information. However, more data are needed on the predictive capacities of PROs. It will also be helpful to obtain more information on how to deal with discordance with physician-reported outcomes in treatment decisions. Furthermore, the links between some PROs and the physiopathology of RA and its treatments appear tenuous or at least incomplete. This poses problems in terms of assessment of treatment efficacy.

PROs are clearly an important part of trials. Looking forward, it will be important to determine if the balance of what is measured is correct, taking into account the different stakeholders' perspectives. As the next years see research advancing in PROs, we will certainly learn more about these aspects, thus helping us to give better care to our patients with RA.

Author affiliations

${ }^{1}$ Sorbonne Universités, UPMC Univ Paris 06, Institut Pierre Louis d'Epidémiologie et de Santé Publique, GRC-UPMC 08 (EEMOIS), Paris, France ${ }^{2}$ Department of Rheumatology, AP-HP, Pitié Salpêtrière Hospital, Paris, France 
${ }^{3}$ Rheumatology Department, Paris Descartes University, Cochin Hospital, AP-HP, Paris, France

${ }^{4}$ INSERM (U1153): Clinical Epidemiology and Biostatistics, PRES Sorbonne Paris-Cité, Paris, France

${ }^{5}$ Arthritis Research UK Centre for Epidemiology, Manchester Academic Health Science Centre, The University of Manchester, Manchester, UK

Acknowledgements The authors thank John Kirwan (UK), Tore K Kvien (Norway) and Maarten de wit (Netherlands) for many helpful discussions on PROs.

Contributors All authors have contributed to this review paper and have agreed with its submission.

Funding WD was supported by a medical research council Clinician Scientist Fellowship (G0902272). LG was partly supported by an Articulum fellowship.

Competing interests None.

Provenance and peer review Not commissioned; externally peer reviewed.

Data sharing statement No additional data are available.

Open Access This is an Open Access article distributed in accordance with the Creative Commons Attribution Non Commercial (CC BY-NC 4.0) license, which permits others to distribute, remix, adapt, build upon this work noncommercially, and license their derivative works on different terms, provided the original work is properly cited and the use is non-commercial. See: http:// creativecommons.org/licenses/by-nc/4.0/

\section{REFERENCES}

1. Scott DL, Lempp HK. Outcomes associated with early rheumatoid arthritis. Expert Rev Pharmacoecon Outcomes Res 2006;6:495-508.

2. http://handbook.cochrane.org/chapter_17/17_patient_reported_ outcomes.htm (accessed 16 Feb 2015).

3. Kirwan JR, Heiberg T, Hewlett SA. Outcomes from the Patient Perspective Workshop at OMERACT 6. J Rheumatol 2003:30:868-72.

4. Kirwan JR, Bartlett SJ, Beaton DE, et al. Updating the OMERACT filter: implications for patient-reported outcomes. J Rheumatol 2014:41:1011-15.

5. Anderson J, Caplan L, Yazdany J, et al. Rheumatoid arthritis disease activity measures: American College of Rheumatology recommendations for use in clinical practice. Arthritis Care Res (Hoboken) 2012;64:640-7.

6. Stoffer MA, Smolen JS, Woolf A, et al. Development of patient-centred standards of care for rheumatoid arthritis in Europe: the eumusc.net project. Ann Rheum Dis 2014;73:902-5.

7. http://www.pcori.org/ (accessed 16 Feb 2015)

8. Smolen JS, Landewé R, Breedveld FC, et al. EULAR recommendations for the management of rheumatoid arthritis with synthetic and biological disease-modifying antirheumatic drugs: 2013 update. Ann Rheum Dis 2014;73:492-509.

9. http://www.fda.gov/downloads/Drugs/Guidances/UCM193282.pdf (accessed 16 Feb 2015)

10. http://www.proqolid.org/ (accessed 16 Feb 2015)

11. http://Olga-QoL.com (accessed 16 Feb 2015).

12. http://oml.eular.org/ (accessed 16 Feb 2015).

13. Kalyoncu U, Dougados M, Daurès JP, et al. Reporting of patientreported outcomes in recent trials in rheumatoid arthritis: a systematic literature review. Ann Rheum Dis 2009;68:183-90.

14. Tugwell $P$, Boers M. Developing consensus on preliminary core efficacy endpoints for rheumatoid arthritis clinical trials. OMERACT Committee. J Rheumatol 1993;20:555-6.

15. Felson DT, Anderson JJ, Boers M, et al. The American College of Rheumatology preliminary core set of disease activity measures for rheumatoid arthritis clinical trials. The Committee on Outcome Measures in Rheumatoid Arthritis Clinical Trials. Arthritis Rheum 1993;36:729-40.

16. Boers M, Tugwell P, Felson DT, et al. World Health Organization and International League of Associations for Rheumatology core endpoints for symptom modifying antirheumatic drugs in rheumatoid arthritis clinical trials. J Rheumatol Suppl 1994;41:86-9.

17. Kirwan JR, Minnock P, Adebajo A, et al. Patient perspective: fatigue as a recommended patient centered outcome measure in rheumatoid arthritis. J Rheumatol 2007;34:1174-7.

18. Aletaha D, Landewe $R$, Karonitsch $T$, et al. Reporting disease activity in clinical trials of patients with rheumatoid arthritis: EULAR/
ACR collaborative recommendations. Ann Rheum Dis 2008:67:1360-4.

19. Kirkham JJ, Boers M, Tugwell $P$, et al. Outcome measures in rheumatoid arthritis randomised trials over the last 50 years. Trials 2013;14:324.

20. Kirwan JR, Hewlett SE, Heiberg T, et al. Incorporating the patient perspective into outcome assessment in rheumatoid arthritisprogress at OMERACT 7. J Rheumatol 2005;32:2250-6.

21. Ahlmen M, Nordenskiöld U, Archenholtz B, et al. Rheumatology outcomes: the patient's perspective. A multicentre focus group interview study of Swedish rheumatoid arthritis patients. Rheumatology 2005;44:105-10.

22. Carr A, Hewlett S, Hughes R, et al. Rheumatology outcomes: the patient's perspective. J Rheumatol 2003;30:880-3.

23. Gossec L, Dougados M, Rincheval N, et al. Elaboration of the preliminary Rheumatoid Arthritis Impact of Disease (RAID) score: a EULAR initiative. Ann Rheum Dis 2009;68:1680-5.

24. http://www.ema.europa.eu/docs/en_GB/document_library/Scientific guideline/2014/06/WC500168852.pdf (accessed 16 Feb 2015).

25. Doward LC, Gnanasakthy A, Baker MG. Patient reported outcomes: looking beyond the label claim. Health Qual Life Outcomes 2010;8:89.

26. Boers M, Kirwan JR, Wells G, et al. Developing core outcome measurement sets for clinical trials: OMERACT filter 2.0. J Clin Epidemiol 2014;67:745-53.

27. Tugwell $\mathrm{P}$, Wells $\mathrm{G}$, Strand $\mathrm{V}$, et al. Clinical improvement as reflected in measures of function and health-related quality of life following treatment with leflunomide compared with methotrexate in patients with rheumatoid arthritis: sensitivity and relative efficiency to detect a treatment effect in a twelve-month, placebo-controlled trial. Leflunomide Rheumatoid Arthritis Investigators Group. Arthritis Rheum 2000;43:506-14.

28. Khan NA, Spencer HJ, Abda E, et al. Determinants of discordance in patients' and physicians' rating of rheumatoid arthritis disease activity. Arthritis Care Res (Hoboken) 2012;64:206-14.

29. French T, Hewlett S, Kirwan J, et al. Different wording of the Patient Global Visual Analogue Scale (PG-VAS) affects rheumatoid arthritis patients' scoring and the overall Disease Activity Score (DAS28): a cross-sectional study. Musculoskeletal Care 2013;11: 229-37.

30. Pincus T, Sokka T, Kavanaugh A. Quantitative documentation of benefit/risk of new therapies for rheumatoid arthritis: patient questionnaires as an optimal measure in standard care. Clin Exp Rheumatol 2004;22(5 Suppl 35):S26-33.

31. Castrejón I, Carmona L, Agrinier N, et al. The EULAR Outcome Measures Library: development and an example from a systematic review for systemic lupus erythematous instruments. Clin Exp Rheum 2015, [Epub ahead of print 23 Mar 2015].

32. Wells G, Li T, Maxwell L, et al. Responsiveness of patient reported outcomes including fatigue, sleep quality, activity limitation, and quality of life following treatment with abatacept for rheumatoid arthritis. Ann Rheum Dis 2008;67:260-5.

33. Gossec L, Paternotte S, Aanerud G, et al. Finalisation and validation of the Rheumatoid Arthritis Impact of Disease (RAID) score: a patient-derived composite measure of impact of RA. A EULAR initiative. Ann Rheum Dis 2011;70:935-42.

34. http://www.nihpromis.org/ (accessed 16 Feb 2015).

35. Hewlett S, Cockshott Z, Byron M, et al. Patients' perceptions of fatigue in rheumatoid arthritis: overwhelming, uncontrollable, ignored. Arthritis Rheum 2005;53:697-702.

36. Nikolaus S, Bode C, Taal E, et al. Fatigue and factors related to fatigue in rheumatoid arthritis: a systematic review. Arthritis Care Res (Hoboken) 2013;65:1128-46.

37. Chauffier K, Salliot $\mathrm{C}$, Berenbaum $\mathrm{F}$, et al. Effect of biotherapies on fatigue in rheumatoid arthritis: a systematic review of the literature and meta-analysis. Rheumatology (Oxford) 2012;51:60-8.

38. Brundage M, Blazeby J, Revicki D, et al. Patient-reported outcomes in randomized clinical trials: development of ISOQOL reporting standards. Qual Life Res 2013:22:1161-75.

39. Dures E, Cramp F, Greenwood R, et al. Reliability and sensitivity of the Bristol RA Fatigue Multidimensional Questionnaire (BRAF-MDQ) and BRAF short scales. Rheumatology (Oxford) 2013;52: 1832-9.

40. Sanderson T, Morris M, Calnan M, et al. Patient perspective of measuring treatment efficacy: the rheumatoid arthritis patient priorities for pharmacologic interventions outcomes. Arthritis Care Res (Hoboken) 2010:62:647-56.

41. Felson DT, Smolen JS, Wells G, et al. American College of Rheumatology/European League against Rheumatism provisional definition of remission in rheumatoid arthritis for clinical trials. Ann Rheum Dis 2011;70:404-13. 